\section{A FIRM SHIFT}

Corporations are known to protect their property. But when it comes to the production of high-quality research, they see value in collaboration. Almost $90 \%$ of the articles that corporate institutions author in the Nature Index are in collaboration with researchers in academic or government labs. And most of these collaborations cross national boundaries.

The number of partnerships between a corporate and an academic or government institution has more than doubled in the five years since 2012, when the index began tracking high-quality research. From an initial 12,672 pairings, the connections have grown to 25,962 in 2016 , half of which were in the life sciences.

Corporations have been cutting back on their research spending and scientific output for several decades, says Robert Tijssen at Leiden University in the Netherlands. "Companies active in science-intensive industries (like pharmaceuticals and biotech) are either outsourcing 'discovery' research or carrying it out more and more with external partners."

A firm-level analysis by researchers at Duke University found that in 1980 the average corporation in the United States published 29 papers a year in the Web of Science database and 16 patents (S10). By 2006, the counts had reversed, with the average firm publishing 12 papers and 35 patents annually. The decline in papers is apparent in every industrial sector, from electronics to telecommunications and the pharmaceutical industry. During the same period, the share of US corporate investment in basic and applied research, as a proportion of total research and development, has shrunk from $26 \%$ to $22 \%$.

While index data tell the story of collaboration, US patent citations show the outsourcing of corporate science. Compared to a decade ago, more patents cite more of the science and engineering literature, but only a small fraction of the cited articles is authored by corporations. A larger, growing share is produced by academic and government institutions.

Overall, corporations contribute to a minor $2 \%$ of high-quality research tracked by the Nature Index. On current trends, their contribution could further diminish.

DATA ANALYSIS BY AARON BALLAGH, BO WU AND WILLEM SLIJP OF THE NATURE INDEX; SHARON BELENZON AND ASHISH ARORA AT DUKE UNIVERSITY; AND ANDREA PATACCONI AT THE UNIVERSITY OF EAST ANGLIA.

\title{
CORPORATE PARTNERS
}

Corporations contributed only $2 \%$ to the authorship of papers in the Nature Index between 2012 and 2016, as measured by weighted fractional count (WFC). The majority of articles (AC) authored by corporations in the index were in collaboration with academic or government research institutes.

Academic $\quad$ Corporate

Non-profit/non-governmental organizations
In collaboration with academic or government research institutions

Only corporates

In collaboration with other institutions
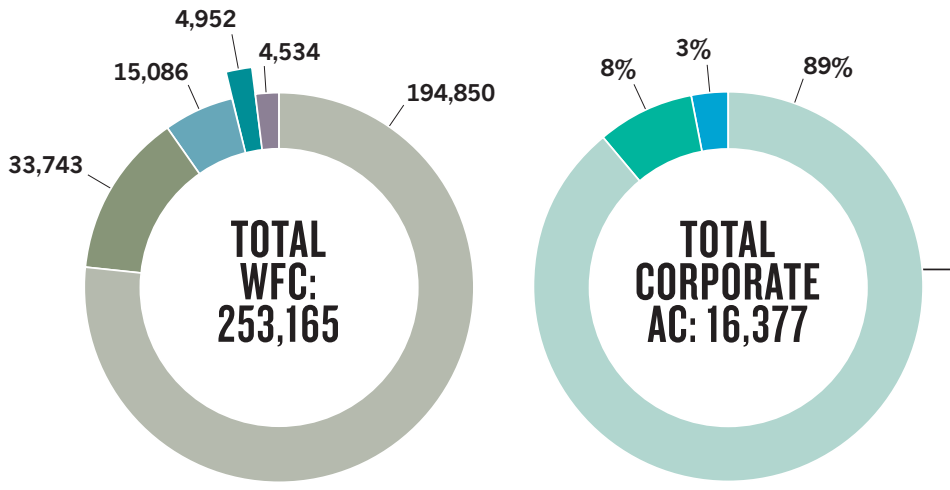

Of the 16,377 articles that corporations contributed to $89 \%$ were co-authored with academic or government institutions.

The number of partnerships between a corporate institution and an academic or government institution in the index has more than doubled over the past five years.

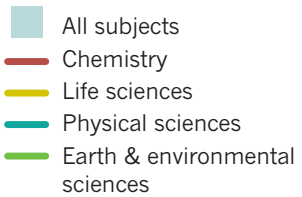

Since 2012, corporate institutions have been collaborating more with academic and government research institutes on international papers, but less on domestic papers.

Internationa

Domestic
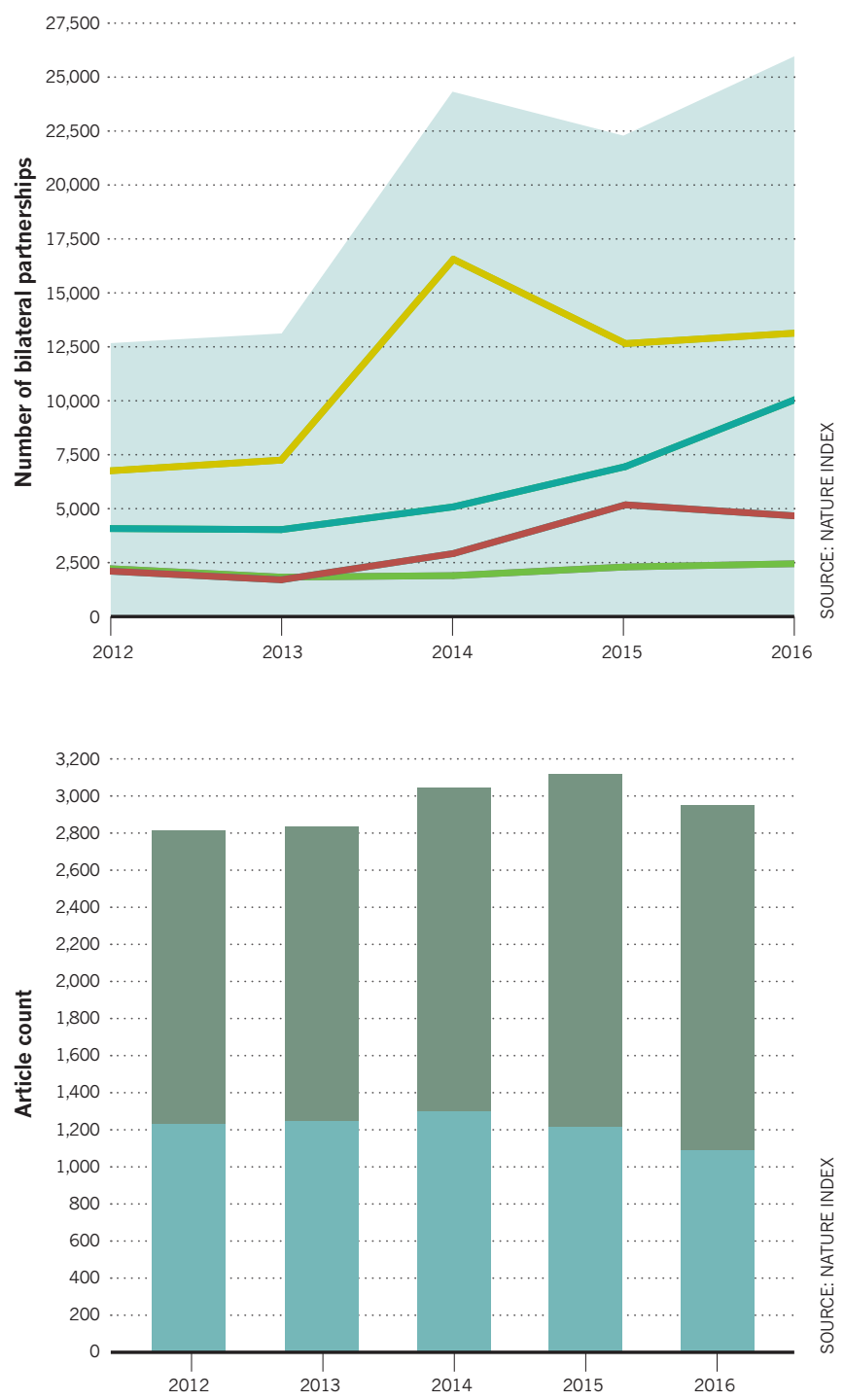
Between 1980 and 2006, the science and engineering publication output of corporations in the United States declined, while their patent output increased.

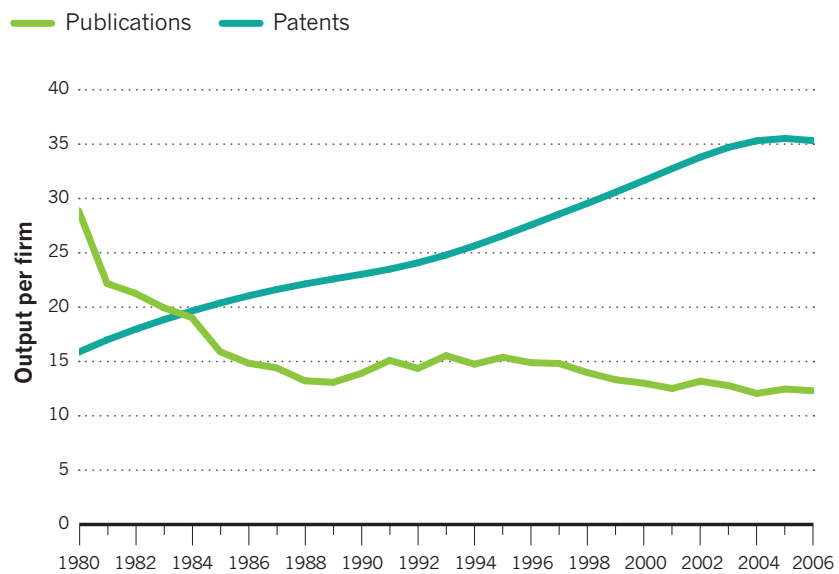

\section{SECTOR SLIDE}

Corporate publication output in the United States has declined across all industrial sectors.

- Electronics/Semiconductor Pharmaceutical industry/Biotech

Chemicals Energy Information technology \& Software

Telecommunication
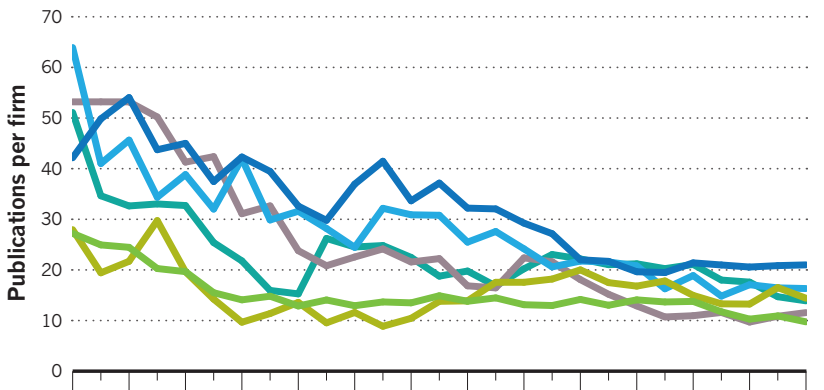

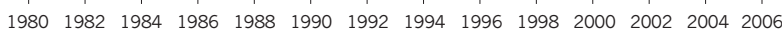

US business investment in basic and applied research made up a small and shrinking share of their total expenditure on research and development.

Development Applied research

Basic research

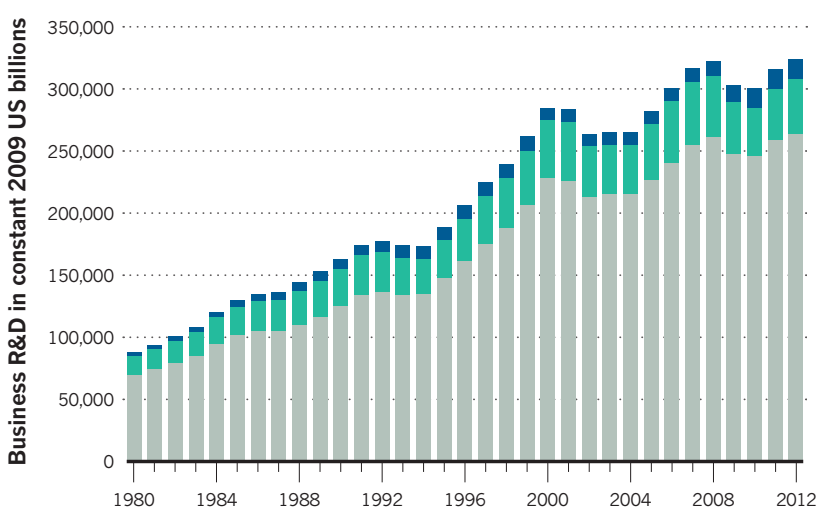

In the Nature Index, global corporate share of paper authorship in the physical sciences has dropped relative to other subjects.

$\begin{array}{ll}\text { Chemistry } & \text { Physical sciences } \\ \text { Life sciences } & \text { Earth \& environmental sciences }\end{array}$

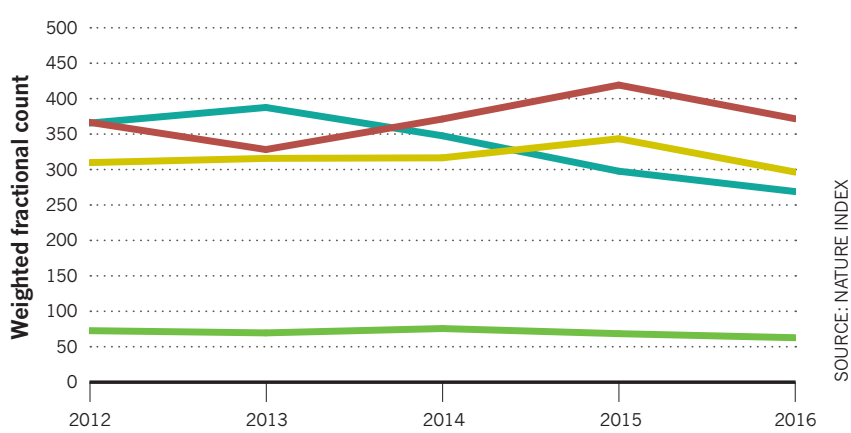

\section{SCIENCE-DRIVEN INNOVATION}

Patents in the United States increasingly cite the science and engineering literature.

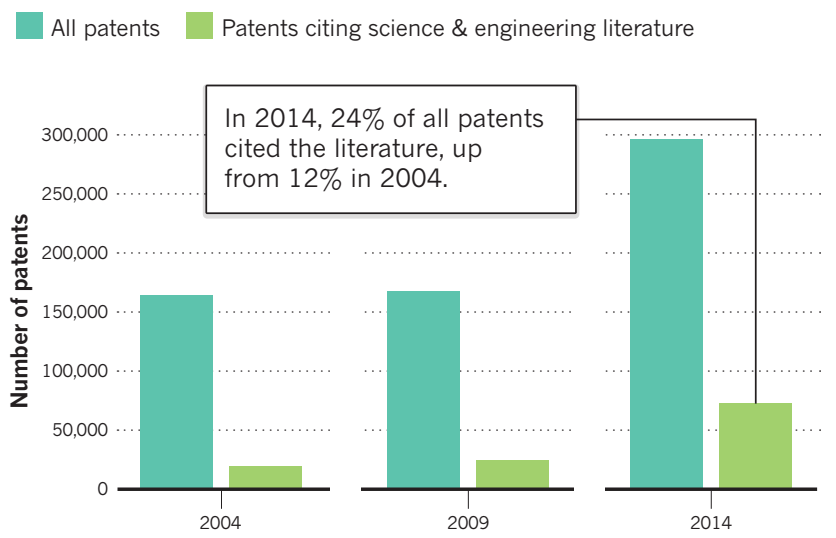

US patents also cite a larger share of the literature. Most of the US papers cited are by government and academic researchers.

US federal government \& academic articles US industry articles Other

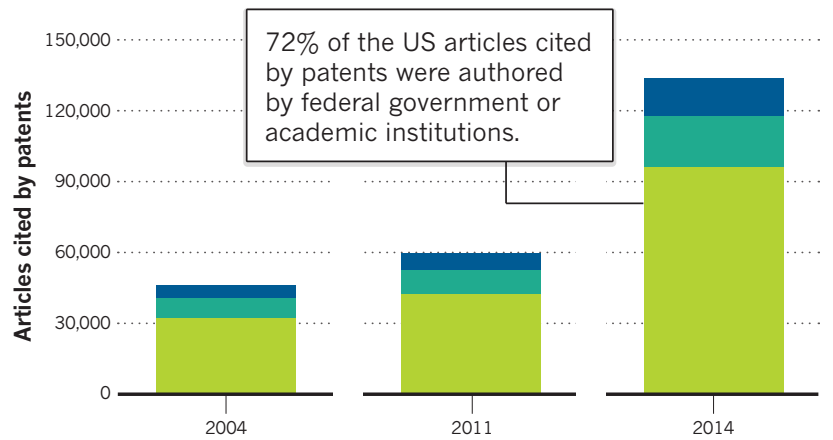

